American Journal of Pharmaceutical Education 2020; 84 (8) Article 7779.

\title{
COMMENTARY
}

\section{The Psychology of Following Instructions and Its Implications}

\author{
Sabrina Dunham, PharmD, ${ }^{a}$ Edward Lee, BS, ${ }^{a}$ Adam M. Persky, PhD ${ }^{\mathrm{a}, \mathrm{b}}$ \\ ${ }^{a}$ University of North Carolina at Chapel Hill, UNC Eshelman School of Pharmacy, Chapel Hill, North Carolina \\ ${ }^{\mathrm{b}}$ Associate Editor, American Journal of Pharmaceutical Education, Arlington, Virginia
}

Submitted July 24, 2019; accepted February 3, 2020; published August 2020.

\begin{abstract}
The ability to follow instructions is an important aspect of everyday life. Depending on the setting and context, following instructions results in outcomes that have various degrees of impact. In a clinical setting, following instructions may affect life or death. Within the context of the academic setting, following instructions or failure to do so can impede general learning and development of desired proficiencies. Intuitively, one might think that following instructions requires simply reading instructional text or paying close attention to verbal directions and performing the intended action afterward. This commentary provides a brief overview of the cognitive architecture required for following instructions and will explore social behaviors and mode of instruction as factors further impacting this ability.
\end{abstract}

Keywords: following instructions, working memory, metacognition, social psychology, teach-back method

\section{INTRODUCTION}

Following instructions is an important ability to practice in everyday life. Within an academic setting, following instructions can influence grades, learning subject matter, and correctly executing skills. In this commentary, we provide an overview of the primary factors that influence the ability of an individual to follow instructions. We translate these findings from the psychological literature into practical guidelines to follow in the educational setting.

Literature on following instructions first surfaced in the late 1970s. ${ }^{1}$ Researchers observed a subset of housewives who demonstrated a preference to tinker with a new home appliance to get it started or watch a demonstration video on how to set it up rather than read the accompanying instruction manual. Since then, numerous factors that influence following instructions have been investigated including a person's working memory capacity, ${ }^{2-6}$ societal rules, ${ }^{7-9}$ history effects, ${ }^{7}$ self-regulatory behavior, ${ }^{10,11}$ and instruction format. ${ }^{3,6}$ Although not completely independent of each other, these factors warrant some individual attention to better understand their implications on following instructions.

Corresponding Author: Adam M. Persky, 325 Beard Hall, CB\#7569, Eshelman School of Pharmacy, University of North Carolina at Chapel Hill, Chapel Hill, NC 27599. Email: apersky@unc.edu

Note: Author Sabrina Dunham is currently a PGY2 cardiology pharmacy resident at Tristar Centennial Medical Center/ University of Tennessee College of Pharmacy in Nashville, Tennessee at time of manuscript acceptance.

\section{Working Memory and Following Instructions}

Working memory is the brain's workbench, linking perception, attention, and long-term memory. ${ }^{12,13}$ As an example, in the classroom setting, learners may receive information visually from slides and/or auditorily from instructor narration. However, only items that learners pay attention to within the environment enter their working memory. These items are then processed, resulting in the formation of a mental representation (ie, encoding) that effectively moves from working memory to long-term storage. Thus, working memory performance is an important intermediary between perception and learning. Because working memory capacity is limited, ${ }^{14}$ a person's ability to follow instructions may be impacted if the instructional load is greater than that capacity, ultimately leading to information loss (for more information, explore cognitive load theory ${ }^{15,16}$ ). This loss of information may be more pronounced when a task must be performed immediately and the presentation rate of instructions cannot be controlled by the user. Imagine a student named Dennis. During class, Dennis is nervous about an upcoming examination and this emotional state preoccupies his working memory, leading to, in that moment, a lower working memory performance. As a result, when the professor gives verbal instructions for an upcoming assignment, the amount of instructional load supersedes Dennis' capacity to hold on to those instructions in his working memory. Because he cannot hold on to those instructions, he is less likely to store them in his long-term memory and will not be able to refer to them later when completing the task. To summarize, the ability 


\section{American Journal of Pharmaceutical Education 2020; 84 (8) Article 7779.}

to hold instructions within working memory is necessary to execute the desired function; thus low working memory performance can compromise a student's ability to follow instructions. $^{2}$ If a student cannot process or hold instructions in working memory, they will probably fail to complete a given task correctly.

There are two potential strategies to assist the learner in this situation. One strategy is to have the learner immediately act on the received information. ${ }^{17}$ A common example of this is the teach-back method, which is a practice of enactment. The practice of enactment has demonstrated greater retention of new information. ${ }^{4,5}$ This line of research has shown that the accuracy of recalling instructions was increased when immediately after instruction, actions were performed at both the initial learning phase (ie, encoding) and later during recall. The second strategy is to use different forms of instructions (eg, written and verbal), which allows the learner to control the rate of presentation. If the learner can control the rate, they can review the instructions as needed or go at a slower pace to fully encode the instructions. ${ }^{18,19}$

\section{Societal Rules and History Effects}

Following instructions is a behavior, and most human behavior depends on social context. Part of the social context is the presence of another individual. The mere presence effect is the phenomenon that human behavior changes when another human is around. ${ }^{9}$ The presence of another person can make an individual more pliant. Being more or less pliant, or pliance, describes behavior that is controlled by a socially mediated consequence. As an example, if an instructor tells a student to write their name at the top of a test sheet and the student does so to gain the instructor's approval, this is a ply and the student is being pliant. Imagine a student, Angela. She follows instructions because she feels it is a professional expectation that her mentors and peers have. Angela will be pliant because following instructions has a social consequence. For this to occur, however, the instructor must monitor the completion of the task, possess the ability to impose a consequence, and observe the effect of the consequence on the student. Donadeli and colleagues ${ }^{8}$ explored the effect of the magnitude of nonverbal consequences, monitoring, and social consequences on instruction following. They observed that the presence of an observer and social reprimand for not following instructions improved the rates at which people followed instructions. This suggests that societal constructs, such as following authority figures and the fear of reprimand, may be drivers in motivating people to follow directions.

There are two possible ways to address societal effects on following instructions. The first way is to establish an expectation of professionalism by explaining why instruction following is important. This would be consistent with aspects of social identity theory. ${ }^{20,21}$ The second way is to create the fear of reprimand. In this case, faculty members hold students responsible for following the rules. This could be with respect to assignment formatting, assignment deadlines, or other aspects that might be tied to a penalty.

Following instructions is affected by the presence of another person even if there is no history of reinforcement for such behavior, suggesting that instructional control may be strengthened by social contingencies. ${ }^{7,8}$ However, societal rules can lead to history effects. If students never receive feedback on or consequences for their inability to follow instructions, history effects dictate they will continue that behavior. Now imagine a student named Amber. Amber wrote down the instructions during class but did not follow them because she generally does well on her assignments despite not completely following the instructions. As such, she abstained from following the rules because a consequence was not associated with not following them.

\section{Metacognition and Self-regulation}

Following instructions also depends on self-regulation, ie, a person's awareness of their own behavior to act in a manner that optimizes their best long-term interests. ${ }^{22}$ To do so, an individual must be aware of their own thoughts and actions. This awareness plays a role in metacognitive monitoring, or a person's monitoring of their own thoughts and behaviors.

Metacognition has been described as thinking about thinking. ${ }^{23}$ At its core, it is about planning, monitoring making progress, and evaluating the completion of a process. For instance, if a student is asked to conduct a journal club meeting, the planning stage would involve gaining an understanding of what is required to successfully complete a journal club meeting. This could include time needed for completion or where to look for an article. The monitoring phase is the awareness to review the article and pull out key information. The final part, evaluation, involves checking the work to determine whether goals were met.

Imagine a student named Craig. Craig wrote down instructions for an assignment, but after completing the assignment, he did not review the instructions to ensure he followed them correctly. He failed to monitor his progress. As such, the ability to be metacognitively aware can be a key piece in following instructions. In this case, individuals may not follow instructions because they are poor monitors of their learning. ${ }^{22,24-28}$ Students may not adequately plan before tackling their assignment, such as 


\section{American Journal of Pharmaceutical Education 2020; 84 (8) Article 7779.}

by reading instructions beforehand. Next, they may not monitor their progress during completion of the assignment. And finally, once students think they have completed the task, they may not go back and read the instructions to ensure they have fulfilled all expectations. To help them with this and other aspects of instruction, students may need to use accountability (societal rules) as a primary source of motivation. Without accountability, students may not follow instructions, thus perpetuating poor metacognitive skills, leading to unawareness of what they know, what they do not know, and the process to correct errors. A strategy may be the use of checklists to help students monitor their thoughts during a process (see Tanner $^{29}$ and Medina and colleagues ${ }^{30}$ for a review of methods to develop metacognition).

\section{Verbal vs Written Instructions}

When examining best practices for conveying instructions to learners, the instructor should consider whether instructions are best retained and applied if received in a verbal versus a written format. To date, no published studies have examined whether one format offers greater benefit over another; however, one study explored both formats in relation to working memory. ${ }^{6}$

Written instructions are efficient because large amounts of detail can be provided that students can read rapidly. Thus, step-by-step manuals can be found for almost all electronic devices. While there is a large body of literature describing the mechanics of how we read, there are some important points to underscore. ${ }^{6}$ When reading and following instructions, a person will act in the same sequence in which action items are presented in the text. In the television show MASH (season 1, episode 20), one of the characters was instructed to "... cut wires leading to the clockwork fuse at the head, but first remove the fuse." He proceeded to cut the wires before removing the fuses. He acted in the same sequence in which the instructions were presented but failed to follow the actual instructions. This raises an important point: individuals are more likely to remember instructions when the order is consistent with how events occur. ${ }^{6}$ Writing instructions according to the sequence of actions the reader needs to take may lead to better results. For example, "do A before doing B' is a superior form of wording instructions than stating, "before doing A, do B," as illustrated in the above scenario.

Spoken instructions are advantageous in face-to-face interactions (eg, within the classroom). Spoken instructions are processed through the phonological loop, a component of working memory focused on verbal information, which is more flexible and convenient. Intrinsically, listening requires less effort than reading. Spoken words can also be paired with visual aids to guide action, such as in measuring blood pressure or administering an immunization. ${ }^{6}$ Remarkably, individuals cannot read and follow visual objects at the same time. Combining text with pictures can be more taxing to working memory than combining spoken words and visuals. A drawback associated with spoken words is the rate of presentation. While the speed at which text is read can be controlled by the end user, the instructor's speed of speech cannot. The phonological loop mediates the ability to hold and process auditory information. ${ }^{13,31}$ Items (bits of information) in the phonological store can rapidly decay, and because items are usually chained in such a way that an item primes the next item, ${ }^{31}$ one lost step can lead to the loss of all subsequent steps (eg, if a student cannot remember step 3 , she is unlikely to recall any step after that). To prevent this loss, people tend to "rehearse" following instructions

Table 1. Common Errors in Following Instructions and Recommendations to Enhance the Probability of Instruction Following

\begin{tabular}{|c|c|c|}
\hline Error in Following Instructions & Potential Cause & Recommendation \\
\hline Students forget parts of the instructions. & $\begin{array}{l}\text { Limited working } \\
\text { memory }\end{array}$ & $\begin{array}{l}\text { 1. Have students teach back the instructions you want } \\
\text { followed. } \\
\text { 2. Give instructions in the order in which they need to be } \\
\text { completed in a stepwise process. } \\
\text { 3. Allow the learners to control the rate of instruction } \\
\text { presentation (verbally or written). }\end{array}$ \\
\hline $\begin{array}{l}\text { Students did not read the instructions } \\
\text { OR students did not follow them/did } \\
\text { not check their work. }\end{array}$ & Metacognitive & $\begin{array}{l}\text { 1. Use checklists to ensure the instructions were followed. } \\
\text { 2. Stage assignments so a larger project is broken into } \\
\text { smaller pieces, allowing better monitoring and feedback. } \\
\text { 3. Include prompts in the assignment to help students } \\
\text { monitor or evaluate the task. }\end{array}$ \\
\hline
\end{tabular}




\section{American Journal of Pharmaceutical Education 2020; 84 (8) Article 7779.}

by repeating the instructions to themselves. ${ }^{3}$ Access to both written instructions and verbal instructions may prove beneficial, as written instructions can be referred to if any verbal instruction is missed.

\section{SUMMARY}

Several factors can impact a student's ability to follow instructions. Recommendations to increase the probability of learners following instructions are available within the literature (Table 1). While these modalities may not guarantee success, these recommendations should increase the probability that most students will follow instructions. Although we cannot extrapolate from current literature whether one mode of instruction delivery is preferred over another, we can apply some of these findings to pharmacy students in a learning environment where instructions are used to guide the completion of deliverables. The first thing the instructor can do is provide both written and verbal instructions. These instructions should be concise, written in student-friendly language, and given in order of operation (ie, step A then step B). Students can read (and reread the written instructions), which should minimize errors resulting from not paying attention or insufficient working memory. Although distracted when verbal instructions were given, a student can review written instructions in a self-paced manner, thus reducing cognitive load and increasing the probability of remembering them. The instructor could then employ metacognitive monitoring and assess the student's understanding of the instructions by including a checklist within the assignment, ie, a strategy to help Craig monitor his learning and check his work (much like journals have checklists for authors). Finally, the instructor should penalize students for not following the instructions thereby using the social context to reinforce their need to follow instructions. Amber benefits by learning there are consequences for not following instructions. For Dennis and Craig, the threat of punishment in the form of lost points may motivate them to review the instructions to ensure they have done their work correctly, a process which can improve their attention (Dennis) and metacognitive monitoring (Craig).

\section{REFERENCES}

1. Wright P, Wilcox P. Following instructions: an exploratory trisection of imperatives. In: Levelt WJM, FLores d' Arcais GB, eds. Studies in the Perception of Language. New York: Wiley;1978. 2. Bergman-Nutley S, Klingberg T. Effect of working memory training on working memory, arithmetic and following instructions. Psychol Res. 2014;78(6):869-877.

3. Yang T-x, Allen RJ, Gathercole SE. Examining the role of working memory resources in following spoken instructions. $J$ Cogn Psychol. 2016;28(2):186-198.
4. Jaroslawska AJ, Gathercole SE, Allen RJ, Holmes J. Following instructions from working memory: why does action at encoding and recall help? Memory Cogn. 2016;44(8):1183-1191.

5. Jaroslawska AJ, Gathercole SE, Logie MR, Holmes J. Following instructions in a virtual school: does working memory play a role? Memory Cogn. 2016;44(4):580-589.

6. Yang T. The role of working memory in following instructions. ProQuest Dissertations Publishing - Dissertation; 2011.

7. Kroger-Costa A, Abreu-Rodrigues J. Effects of historical and social variables on instruction following. Psychol Record. 2012;62(4):691-706.

8. Donadeli JM, Strapasson BA. Effects of monitoring and social peprimands on instruction-following in undergraduate students. Psychol Record. 2015;65(1):177-188.

9. Guerin B. Mere presence effects in humans: a review. J Exp Soc Psychol. 1986;22(1):38-77.

10. de Bruin $\mathrm{ABH}$, van Gog T. Improving self-monitoring and selfregulation: from cognitive psychology to the classroom. Learn Instruct. 2012;22(4):245-252.

11. Bruin ABH, Dunlosky J, Cavalcanti RB. Monitoring and regulation of learning in medical education: the need for predictive cues. Med Educ. 2017;51(6):575-584.

12. Baddeley A. Working memory. Current Biol. 2010;20(4): R136-R140.

13. Cowan N. Working memory underpins cognitive development, learning, and education. Educ Psychol Rev. 2014;26(2):197-223. 14. Cowan N. The magical number 4 in short-term memory: a reconsideration of mental storage capacity. Behav Brain Sci. 2001;24(1):87-114.

15. Van Merriënboer JJG, Sweller J. Cognitive load theory in health professional education: design principles and strategies: cognitive load theory. Med Educ. 2010;44(1):85-93.

16. Young JQ, Van Merrienboer J, Durning S, Ten Cate O. Cognitive load theory: implications for medical education: AMEE Guide No. 86. Med Teach. 2014;36(5):371-384.

17. Allen RJ, Waterman AH. How does enactment affect the ability to follow instructions in working memory? Memory Cogn. 2015; 43(3):555-561.

18. Grech V. The application of the Mayer multimedia learning theory to medical PowerPoint slide show presentations. $J$ Visual Comm Med. 2018;41(1):36-41.

19. Mayer RE. Applying the science of learning: evidence-based principles for the design of multimedia instruction. Am Psychol. 2008;63(8):760-769.

20. Jha V, Brockbank S, Roberts T. A framework for understanding lapses in professionalism among medical students: applying the theory of planned behavior to fitness to practice cases. Acad Med. 2016;91(12):1622-1627.

21. Burford B. Group processes in medical education: learning from social identity theory. Med Educ. 2012;46(2):143-152.

22. Sitzmann T, Ely K. A meta-analysis of self-regulated learning in work-related training and educational attainment: what we know and where we need to go. Psychol Bull. 2011;137(3):421-442.

23. Flavell JH. Metacognition and cognitive monitoring: a new area of cognitive-developmental inquiry. Am Psychol. 1979;34(10): 906-911.

24. Dunning D, Heath C, Suls JM. Flawed self-assessment: implications for health, education, and the workplace. Psychol Sci Public Interest. 2004;5(3):69-106.

25. Kornell N, Bjork RA. The promise and perils of self-regulated study. Psychonom Bull Rev. 2007;14(2):219-24. 


\section{American Journal of Pharmaceutical Education 2020; 84 (8) Article 7779.}

26. Dunlosky J, Lipko AR. Metacomprehension: a brief history and how to improve its accuracy. Curr Dir Psychol Sci. 2007;16(4): 228-232.

27. Dunlosky J, Rawson KA. Overconfidence produces underachievement: inaccurate self evaluations undermine students' learning and retention. Learn Instruct. 2012;22(4):271-280.

28. Bjork RA, Dunlosky J, Kornell N. Self-regulated learning: beliefs, techniques, and illusions. Ann Rev Psychol. 2013;64(1):417-44.
29. Tanner KD. Promoting student metacognition. CBE Life Sci Educ. 2012;11(2):113-120.

30. Medina MS, Castleberry AN, Persky AM. Strategies for improving learner metacognition in health professional education. Am J Pharm Educ. 2017;81(4):78.

31. Baddeley AD, Larsen JD. The phonological loop unmasked? a comment on the evidence for a "perceptual-gestural" alternative. Quart J Exp Psychol. 2007;60(4):497-504. 